\title{
Studia Augustana
}

Augsburger Forschungen

zur europäischen Kulturgeschichte

Im Auftrag des

Instituts für Europäische Kulturgeschichte

herausgegeben von

Johannes Burkhardt, Johannes Janota

und Helmut Koopmann

Band 12 



\section{Adam Reißner Gesangbuch}

Herausgegeben

und in Zusammenarbeit mit Ute Evers kommentiert von Johannes Janota

I. Faksimile der Augsburger Handschrift

Max Niemeyer Verlag Tübingen 2004 
Gedruckt mit Unterstützung der Gesellschaft der Freunde der Universität Augsburg und der Stadtsparkasse Augsburg

Bibliografische Information der Deutschen Bibliothek

Die Deutsche Bibliothek verzeichnet diese Publikation in der Deutschen Nationalbibliografie; detaillierte bibliografische Daten sind im Internet über $b t t p: / / d n b . d d b$.de abrufbar.

ISBN 3-484-16512-X ISSN 0938-9652

(C) Max Niemeyer Verlag GmbH, Tübingen 2004

bttp://wwre.niemeyer.de

Das Werk einschließlich aller seiner Teile ist urheberrechtlich geschützt. Jede Verwertung außerhalb der engen Grenzen des Urheberrechtsgesetzes ist ohne Zustimmung des Verlages unzulässig und strafbar. Das gilt insbesondere für Vervielfältigungen, Übersetzungen, Mikroverfilmungen und die Einspeicherung und Verarbeitung in elektronischen Systemen.

Printed in Germany.

Druck: Gulde-Druck GmbH, Tübingen

Einband: Norbert Klotz, Jettingen-Scheppach 